\title{
Water Bath
}

National Cancer Institute

\section{Source}

National Cancer Institute. Water Bath. NCI Thesaurus. Code C112508.

A device designed to regulate the temperature of a vessel by bathing it in water held at the desired temperature. 